\title{
António da Silva Leite e a música para voz e três órgãos do Convento de Santa Clara da cidade do Porto
}

\section{António da Silva Leite and the music for voice and three organs from the Convent of Santa Clara of Oporto}

\author{
(iD \\ Rosana Marreco Brescia \\ Centro de Estudos de Sociologia e Estética Musical, Universidade NOVA de Lisboa, Portugal \\ rbrescia@fcsh.unl.pt
}

Resumo:Considerado entreosmaisimportantes eversáteiscompositores portugueses da virada dos séculos XVIII e XIX, António da Silva Leite ocupou posições de grande prestígio na cidade do Porto. Foi Mestre de Capela da Sé Catedral, organista da Santa Casa de Misericórdia, diretor artístico e compositor do Teatro de São João e, em especial, foi mestre de música e compositor dos mais importantes conventos femininos da cidade. O presente artigo aborda o papel desse ilustre músico junto às freiras clarissas do Porto, virtuosas cantoras e instrumentistas que comissionaram diversas obras para serem executadas nas mais importantes celebrações do calendário litúrgico. Dentre as dezenas composições de António da Silva Leite dedicadas às freiras de Santa Clara, destacam-se as obras compostas para vozes acompanhadas por três órgãos, um exemplo singular na história da música portuguesa onde o património organológico previamente existente acabou por servir como agência para a produção de um repertório musical único.

Palavras-chave: Música Conventual. António da Silva Leite. música no Porto. Convento de Santa Clara. Freiras musicistas.

Abstract: Considered amongst the most important and versatile Portuguese composers from the transition of the 18th and 19th centuries, António da Silva Leite occupied the most prestigious positions 
of the city of Oporto. He was Chapel Master of the Cathedral, organist in the distinguished Santa Casa de Misericórdia, artistic director and composer of the Teatro de São João, and music teacher and composer of the main female convents of the city. The present paper approaches the role of this eminent composer and his relationship with the Clarisse nuns of Oporto, virtuosi singers and instrumentalists who commissioned several works to be performed in the most important celebrations of the liturgical calendar. Amongst the many compositions by Silva Leite dedicated to the nuns of Santa Clara, stands out the works composed for voices accompanied by three organs, an extraordinary case in the history of Portuguese music where the existing organological heritage worked as an agency to produce a unique musical repertoire.

Keywords: Conventual Music. António da Silva Leite. Oporto Music. Convent of Santa Clara. Musician Nuns.

Submetido em: 10 de maio de 2021

Aceito em: 1 de agosto de 2021 
António da Silva Leite e a música para voz e três órgãos do Convento de Santa Clara... Rosana Marreco Brescia

Nascido em 23 de maio de 1759 na Rua da Fonte Taurina, no coração da Ribeira do Porto, Portugal, António da Silva Leite era filho de Luís da Silva Leite e Thomazia Maria de Souza'1. Assim como um de seus irmãos, recebeu formação religiosa - chegando a receber as Ordens Menores (in minoribus), contudo não seguiu com a carreira sacerdotal para exercer a profissão de músico (BESSA, 2008. 24-25). Não se sabe muito acerca de sua formação, mas Ernesto Vieira levanta a hipótese de que Silva Leite tivesse sido pupilo de Girolamo Sertori (VIEIRA, 1900. 19-20), músico natural de Parma que esteve no Porto na década de 1760. Contudo, os manuscritos da autoria de Sertori conservados na Biblioteca Nacional de Portugal indicam que o compositor residiu na cidade invicta entre os anos de 1764 e 1765, sendo pouco provável que com 5 ou 6 anos de idade Silva Leite já estudasse com um reconhecido músico estrangeiro. Já hipótese de que grande parte da formação de Silva Leite tenha sido autodidata é reforçada na dedicatória de seu Estudo de Guitarra, onde escreve:

O desejo de ser útil aos Patrícios amantes da Música, concorrendo com as minhas fracas luzes, alcançadas pelo estudo, e aplicação em que tenho empregado desde a infância; concorrendo, digo, para o aproveitamento dos que se deleitaõ com o honesto, e grato prazer que causa esta Arte Scientifica, de que também resulta em parte a cultura das grandes Cidades (...) (1796, 3).

O pesquisador Rui Manuel Pereira Bessa levanta a possibilidade de que António da Silva Leite tivesse desistido da carreira eclesiástica por não contar com os meios financeiros requeridos pela diocese, já que os bens da família tinham sido destinados à formação do irmão mais velho, como era costume na época. Tal hipótese é reforçada pelo fato de que a cidade do Porto oferecia consideravelmente menos oportunidades de trabalho para um músico profissional do que a corte de Lisboa (2008, p. 28-33), sendo a carreira eclesiástica muito mais estável e promissora. Talvez da falta de oportunidades

$\overline{1 \text { Arquivo Distrital do }}$ Porto, L $\mathrm{B} 6$, Fol.126v. 
António da Silva Leite e a música para voz e três órgãos do Convento de Santa Clara... Rosana Marreco Brescia

estáveis provenha a versatilidade do compositor, que trabalhou para muitas instituições desempenhando funções de compositor, organista, cantor, professor, mestre de capela, diretor artístico e mestre de cerimónias.

Silva Leite foi contratado em 1779 como organista da Igreja da Santa Casa da Misericórdia do Porto² (BESSA, 2008. 46), um dos mais importantes postos para um músico profissional na cidade. Ao prestígio da instituição, acresce-se o fato de que Silva Leite fora contratado com apenas 20 anos de idade, o que deixa evidente que desde muito cedo o compositor já era reconhecido por seus conterrâneos.

O compositor também trabalhou como Mestre de Cerimónias para muitas das festividades realizadas na cidade do Porto. $\mathrm{Na}$ época, todas as grandes festas realizadas na cidade, tanto civis como religiosas, contratavam um músico de prestígio que, além de dominar a sua arte, tinha experiência na contratação de instrumentistas e cantores, ajustando os salários e cuidando de todo o processo administrativo para que a música da festa em questão fosse executada sem percalços. Assim, António da Silva Leite foi o responsável pela execução do Te Deum, na capela da Sé Catedral, no dia 5 de outubro de 1808, pela Restauração da Independência de Portugal e pela libertação da cidade do Porto do domínio francês. A mesma efeméride foi comemorada pelos militares da cidade no Templo dos Meninos Órfãos, onde dois coros de música instrumental e vocal interpretaram composições de António Leal Moreira, além da Sinfonia da Restauração, composta pelo próprio Silva Leite, como afirma o periódico $O$ Leal Portuguez (1808, p. 272). Ao que tudo indica, António da Silva Leite exerceu a função de mestre de cerimónias ao longo de sua vida, concomitantemente com os demais trabalhos acima citados. Em 1828, uma cerimónia em ação de graças pela coroação de D. Miguel foi realizada no Templo de São João Novo, como descreve a revista $O$ Tripeiro:

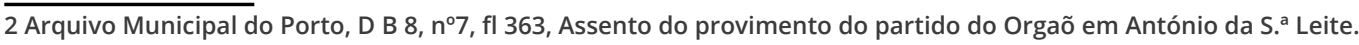


António da Silva Leite e a música para voz e três órgãos do Convento de Santa Clara... Rosana Marreco Brescia

Huma estrondosa Orquestra, e immenso número de vozes, reunindo os melhores Professores de Música da Cidade, regidos pelo honrado Antonio da Silva Leite, insigne Mestre de Capella desempenháraõ assombrosamente a Solemne, a pomposa Missa, que aquelle grãde Mestre havia escolhido com preferencia, por ser ao gosto, e na harmonia da Opera Sacra Moysés no Egypto (1909, p. 260).

António também teve uma relação próxima com o teatro lírico da segunda mais importante cidade portuguesa. O Teatro de São João, inaugurado em 13 de maio de 1798 - dia do nascimento do príncipe regente D. João -, teve António da Silva Leite como diretor musical nos primeiros anos do século XIX³ (BESSA, 2008. 79). O maestro portuense dirigiu a orquestra na execução das óperas La Griselda, com música do mestre de capela parmigiano Ferdinando Paer, e La Morte di Cleopatra, de Sebastiano Nasolini4, ambas interpretadas por cantores italianos contratados em Lisboa (CRANMER, 2020, p. 159). A partir do ano seguinte, Silva Leite passa a constar nos libretos também como compositor do teatro. Segundo Inocêncio da Silva, foi autor de ao menos duas óperas, nomeadamente L'Astuzia delle Donne e I Pungegli per Equivoco, representadas em 1807 no Teatro de S. João (1867, p. 306).

Foi nesse período que Silva Leite passou a trabalhar para a Capela da Sé Catedral do Porto, que, apesar de ser menos reconhecida do que suas congêneres em Lisboa, Braga ou Évora, e de oferecer salários mais modestos, era uma das instituições mais importantes da cidade do Porto no início do século XIX. Silva Leite já era o mestre de capela da catedral portucalense na época da expulsão dos franceses, quando o governador e o bispo determinaram que se celebrasse a ocasião com festejos em agradecimento ao Altíssimo. O periódico O Leal Português, em 5 de Outubro de 1808, escreve:

3 Arquivo Histórico do Porto, Lํ de Vereações de 1805.

4 Obra interpretada no Real Teatro de São João em 8 de Novembro de 1807, em noite em benefício da célebre cantora Marianna Scaraelli. 
António da Silva Leite e a música para voz e três órgãos do Convento de Santa Clara... Rosana Marreco Brescia

tomou S. Ex. a os paramentos Pontificaes, e expondo-se entaõ o SANTISSIMO SACRAMENTO, entoou o Te Deum, que cantou huma grande Orquestra de escolhidos musicos, regidos pelo Mestre de Capella da Cathedral Antonio da Silva Leite (1808, p. 131).

Concomitantemente com a atividade de organista, Silva Leite foi professor de cravo, guitarra e viola - instrumentos que dominava. A guitarra parecia ser o seu instrumento predileto e para ela compôs seis sonatas com acompanhamento de violino e duas trompas, além de minuetes, contradanças, marchas e alegros para uma ou duas guitarras. Foi um renomado professor deste instrumento, tendo tido inúmeros alunos - o que o levou a publicar o já mencionado Estudo de Guitarra (1796).

Entre sua produção de música profana, não se pode deixar de mencionar as Modinhas. António da Silva Leite foi um dos muitos compositores portugueses que se debruçaram sobre o género, tão popular nos saraus realizados nos inúmeros salões nobres e burgueses do reino, aquém e além-mar. Foi autor de muitas modinhas a duas vozes acompanhadas por uma ou duas guitarras e por outros instrumentos, como viola, baixo, pianoforte ou bandolim. O fato do gênero ser amplamente cultivado tanto em Portugal como no Brasil, aliado à relativa facilidade na circulação de bens e pessoas que existia entre as duas partes do reino muito intensificada após a transferência da corte portuguesa para o Rio de Janeiro em 1808 -, possibilitou ao compositor portuense apropriar, em algumas das suas obras profanas, elementos particulares da música brasileira sem jamais ter saído de Portugal, como por exemplo na obra Xula Carioca, publicada em Lisboa, no Jornal de Modinhas (1795).

António da Silva Leite foi também autor de uma coleção manuscrita de exercícios intitulada Arte da Música, do Rezumo de todas as regras, e preceitos da Cantoria, assim da Métrica, como do Cantochão e da obra intitulada O organista instruído. A inigualável versatilidade do compositor portuense levou-o a escrever também 
António da Silva Leite e a música para voz e três órgãos do Convento de Santa Clara... Rosana Marreco Brescia

obras teatrais. As peças teatrais Alardo na Aldêa, impressa em 1802, e As agoas férreas são atribuídas à Silva Leite (CRANMER, 2020, p. 157).

Silva Leite foi o autor de Elogios e Sonetos, alguns dos quais dedicados a monjas clarissas, como no caso de um soneto dedicado à senhora Anna Cândida, publicado em 18265. Também um Soneto de Aplauso pela reeleição de D. Maria Bárbara Bellon como abadessa do Convento de Monchique foi publicado por Silva Leite em 1829. Em razão destas obras literárias e das inúmeras obras compostas para serem interpretadas pelas freiras de diversos conventos da cidade do Porto, constata-se que Silva Leite sempre manteve uma estreita relação com a vida conventual ao longo de sua atividade profissional.

Silva Leite se estabeleceu como um homem que transitava em todos os meios culturais de uma importante cidade, atuando com o mesmo empenho em diferentes funções tanto para instituições civis como eclesiásticas. Segundo um manuscrito intitulado Livro de Óbitos de professores de música que tem falecido na cidade do Porto:

incontrandose em alguma soirée ninguém podia estar triste; pondo-se ele a cantar do som da viola, ou do cavaquinho; era morrer com riso, ou recitando versos (era Poeta) ou contando historietas: muito chistoso: e de bons ditos, e tinha felizes lembranças" (f.13r)

5 SILVA LEITE, António. Em Applauso da Exc.ma Snr.a D. Anna Candida no dia dos seus anos, e no qual fez a sua solemne profissão no Real Convento das Religiosas de Santa Clara da Cidade do Porto...: Soneto. Porto: Imprensa do Gandra, 1826. BNP, L.598//10 A.

6 Apud: CRANMER, David. Op.cit., p.157. 
António da Silva Leite e a música para voz e três órgãos do Convento de Santa Clara... Rosana Marreco Brescia

Figura 1 - Caricatura de António da Silva Leite

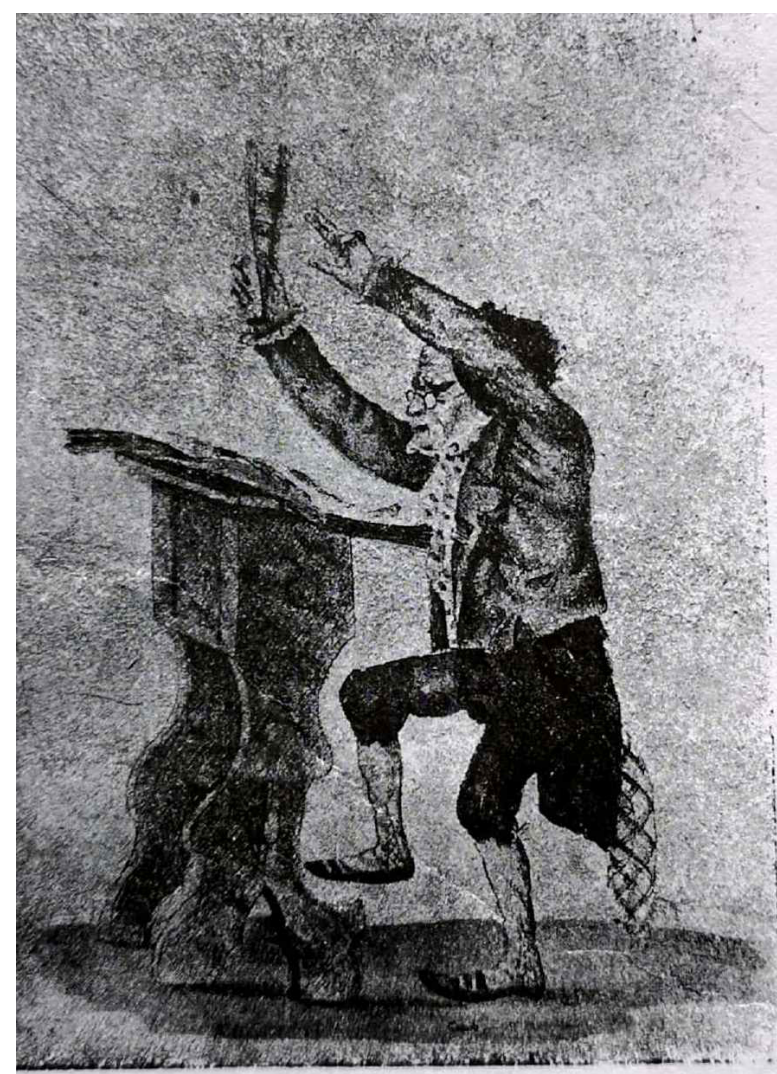

ANTÓNIO DA SILVA LEITE

Mestre-capela

Caricatura do senógrafo Couto. (Coleç̧ăo P. Vitorino)

\section{O Porto, o Convento de Santa Clara e a Música}

A importância da cidade do Porto tornou-se ainda mais evidente a partir de meados do século XVIII, quando o comércio estabelecido com reinos estrangeiros, nomeadamente o de vinho do Porto, possibilitou uma considerável ascensão da burguesia. Em meados dos setecentos, a cidade invicta contava com quinze conventos masculinos e femininos, muitos construídos nos séculos anteriores, mas reconstruídos, ampliados ou reformados a partir de princípios do século XVIII, graças à boa situação financeira 
António da Silva Leite e a música para voz e três órgãos do Convento de Santa Clara... Rosana Marreco Brescia

da cidade e seus habitantes. Os edifícios religiosos não apenas dominavam sobremodo a paisagem urbana da cidade invicta, como eram também importantes polos de produção cultural.

Dentre os conventos femininos havia o de Santa Clara, fundado em 1416; o de São Bento da Avé Maria, fundado em 1528; o da Madre de Deus de Monchique, fundado em 1545 e o de São José e Santa Teresa, fundado em 1704 (COSTA, 1706, p. 352-353). O Convento de Santa Clara, fundado pelo rei D. João I (FERNANDES, 1992, p. 27), contava, em princípios do século XVIII, com pouco mais de cem religiosas nas suas dependências, tornando-se o segundo maior da cidade, atrás apenas do Real Convento de São Bento da Avé-Maria - que segundo o Padre António Carvalho da Costa, tinha mais de 130 religiosas vivendo em suas dependências. A situação financeira das freiras residentes no convento das clarissas em princípios do século XVIII possibilitou que fosse implementado um grande programa de remodelação das suas dependências, sobretudo da igreja conventual. A partir de 1729, foram realizadas obras que incluíram a construção dos retábulos em talha dourada, pinturas decorativas, a encomenda de novas imagens devocionais e a compra de dois órgãos - um positivo e um grande órgão -, para melhor servirem às cantoras de Santa Clara. O interior da igreja, felizmente ainda preservado, é considerado um dos melhores exemplos de arquitetura e decoração religiosa portuguesa do século XVIII (SMITH, 1962, p. 111).

Paralelamente às reformas realizadas no Convento de Santa Clara, foi também na primeira metade do século XVIII que a música portuguesa, sobretudo a de caráter religioso, passou por uma inexorável transformação. O interesse do monarca D. João $V$, particularmente voltada para a produção de uma música religiosa de alto nível, o levou a criar subsídios que permitissem que promissores compositores portugueses estudassem por um período em Roma. Tal fato foi um verdadeiro divisor de águas no que tange à produção musical do reino, que passou a ter como modelo máximo a música e os músicos ao serviço da Cappella Giulia. Além dos portugueses que foram para Roma, músicos e 
António da Silva Leite e a música para voz e três órgãos do Convento de Santa Clara... Rosana Marreco Brescia

artistas italianos eram constantemente contratados para trabalhar em Portugal, não somente na corte de Lisboa, como também em outras importantes cidades do reino. Um significativo número de partituras musicais foi comissionado pelas freiras dos conventos femininos portugueses, tanto a compositores italianos residentes no reino, como Valentino Fioravanti, David Perez e Giuseppe Totti; como a outros que nunca pisaram solo português, como Giovanni Paisiello, Domenico Monbelli e Nicola Porpora ${ }^{7}$.

O altíssimo nível das capelas musicais de algumas ordens religiosas era notório em grande parte do mundo católico. Em conventos como o de Santa Clara da cidade do Porto, onde uma considerável parte da elite ingressava as suas filhas, o nível cultural das freiras era significativamente elevado, já que a educação proporcionada às jovens da alta sociedade incluía a literatura (MORUJÃO, 2011, p. 48) e a música, muitas vezes antes mesmo da entrada no convento. O conhecimento musical era altamente estimado no momento do ingresso de uma jovem num convento como o de Santa Clara, onde a música era amplamente cultivada e valorizada. Algumas famílias de recursos mais escassos poderiam economizar um montante expressivo caso a postulante ao convento fosse uma boa cantora ou proficiente em algum instrumento musical - especialmente o órgão (MONSON, 2012, p. 3) -, já que, para que a atividade do convento prosseguisse segundo os preceitos, era essencial a presença de uma organista. Possuir uma sólida formação musical poderia também colocar a jovem em questão na classe dominante do convento, onde ela seria dispensada de tarefas relacionadas ao dia a dia do convento. Ou seja, os dotes musicais eram uma grande vantagem não só no momento do ingresso, mas também uma vez dentro da instituição.

De fato, ingressar num convento em Portugal no século XVIII poderia ser muito mais interessante do que permanecer na casa da família, já que, uma vez internas, as aspirantes tinham muito mais contato com outras mulheres - e por vezes até com homens, em comparação com outras mulheres de elite solteiras ou mesmo

7 Diversos manuscritos desses compositores fazem parte do espólio dos antigos conventos femininos preservado na seção de música da Biblioteca Nacional de Portugal. 
António da Silva Leite e a música para voz e três órgãos do Convento de Santa Clara... Rosana Marreco Brescia

casadas. Os conventos femininos eram verdadeiros palcos de representações poéticas, musicais e teatrais (LOPES, 1989, p. 53), sem que as intérpretes fossem malvistas pela sociedade daquele tempo e sem que as suas respetivas famílias tivessem sua reputação diminuída. As muitas festividades religiosas realizadas ao longo do ano litúrgico tinham a música como um elemento de destaque, e a qualidade da mesma muitas vezes determinava a afluência a um determinado convento em detrimento de outro (FERNANDES, 1997/98, p. 67).

A música interpretada nos conventos femininos portugueses era variada, indo desde o cantochão à polifonia, passando pelo repertorio instrumental - sacro e profano. Alguns dos conventos eram mais rígidos na adequação da música ao culto litúrgico, mas outros, como o Convento de Santa Clara do Porto, permitiam que música com uma maior influência operística fosse executada, o que, além de melhor exibir as qualidades técnico-vocais das freiras intérpretes, era muito mais atrativo para o público que frequentava as cerimónias. Prova do interesse do público pela música de influência operística ou profana pode ser encontrada num interessante relato deixado pelo Padre Teodoro de Almeida do Convento das Saboianas de Belém pela ocasião a visita do viajante inglês William Beckford:

Em música não somos muito fortes. Não permitimos modinhas, nem árias de ópera: um cantochão é tudo o que podeis esperar. Em suma, não somos dignos de receber tão distintos visitantes, e não temos nada do que o mundo chama interessante, para nos recomendar (1901, p. 56-57).

Numa cidade onde a oferta cultural de caráter público era restrita às representações do Teatro de São João, os conventos femininos proporcionavam excelentes chances para se ouvir boa música. E as grandes festividades do ano litúrgico proporcionavam ocasiões para que as melhores intérpretes dos conventos 
António da Silva Leite e a música para voz e três órgãos do Convento de Santa Clara... Rosana Marreco Brescia

comissionassem novas partituras para serem executadas pelas religiosas cantoras ou instrumentistas.

Dentre considerável acervo pertencente ao antigo Convento de Santa Clara preservado na secção de música da Biblioteca Nacional de Portugal destacam-se os nomes dos compositores Frei Francisco de São Boaventura e António da Silva Leite, autor de mais de três dezenas de obras para as freiras do Convento de Santa Clara do Porto, datadas da década de 1790 até ao ano de 1828. Destacam-se as obras destinadas às cerimónias de Natal e Semana Santa, as principais dentro do calendário litúrgico.

O musicólogo Robert Stevenson afirma que António da Silva Leite teria sido organista do Convento de Santa Clara (2020), o que parece pouco provável, já que esta função era ocupada também pelas freiras. Algumas partituras ainda conservadas trazem nomes de freiras-organistas, como é o caso de Camila Henriqueta de Saldanha, a quem é dedicado o Divertimento em Lá menor ${ }^{8}$; e Catharina Cândida, a quem é dedicada a curiosa Gaita Descançada para Órgão para além do Discurso para Órgão em Dó Maior 9 , ambas atribuídas a Francisco de São Boaventura. A identificação do convento portuense onde as referidas organistas residiam não foi possível, mas não é descartada a hipótese de que fossem clarissas.

O certo é que António da Silva Leite manteve uma relação profissional com as freiras de Santa Clara, tanto como professor de música como compositor que atendia aos pedidos das religiosas para que novas obras fossem compostas ou adaptadas para ocasiões especiais. A Lectio VII a Solo e Órgão De Epistola prima Beati Pauli, escrita em 1796 para D. Quitéria Emília, traz no seu frontispício a indicação de que a religiosa era pupila do maestro ${ }^{10}$. Outra obra dedicada à celebre freira Maria Peregrina, a Lectio $6^{a}$ in Coena Domini, menciona que a jovem era na época noviça do convento ${ }^{11}$. Nascida em 1783, esta freira ingressou muito jovem no Convento

8 Biblioteca Nacional de Portugal. Divertimento para Órgão dedicada a Ex.ma Snr.a D.a Camila Henriqueta de Saldanha. m.m.4514.

9 Biblioteca Nacional de Portugal. Gaita Descançada dedicada a Soror Catharina Candida. m.m.5099.

10 Biblioteca Nacional de Portugal. SILVA LEITE, António da. Lectio VII a solo e órgão. m.m.1227.

11 Biblioteca Nacional de Portugal. SILVA LEITE, António da. Lectio $6^{\text {a }}$ In Coena Domini m.m.2149 
António da Silva Leite e a música para voz e três órgãos do Convento de Santa Clara... Rosana Marreco Brescia

de Santa Clara, com pouco mais de 10 anos completos, tomando o hábito de pupila no dia 19 de junho de $1797^{12}$. Contudo, desde 1794 já demonstrava inclinação para o canto, tendo sido aluna de Francisco de São Boaventura. É natural que a sua orientação fosse transferida para António da Silva Leite após a morte do frei carmelita.

Segundo os manuscritos preservados na Biblioteca Nacional de Portugal, a relação de Silva Leite com as freiras do Convento de Santa Clara começa na década de 1790 - mais precisamente do ano de 1796 -, e vai até aproximadamente 1828. Em pouco mais de duas décadas, o compositor estabelece uma estreita colaboração com as religiosas-cantoras, já que em muitas de suas obras é possível notar não só a evolução vocal de uma determinada cantora, mas também como características técnico-interpretativas eram rigorosamente levadas em consideração pelo maestro, o que seria muito mais difícil de ser observado por um compositor completamente alheio à vida musical do convento. Os laços de admiração e de amizade estabelecidos entre o compositor e algumas das freiras ficam evidentes não somente nas composições musicais, como também nas obras literárias anteriormente citadas.

\section{As Obras para Três Órgãos e Canto}

O Convento de Santa Clara parece ter sido um dos raros conventos femininos em Portugal que contavam com três órgãos em funcionamento concomitantemente nas primeiras décadas do século XIX, o que permitiu que um repertório absolutamente singular fosse composto para as clarissas portuenses a partir de 1803, quando o terceiro instrumento foi adquirido.

Quem hoje entra na Igreja do antigo Convento de Santa Clara depara-se com duas belíssimas caixas de órgão da primeira metade do século XVIII. No entanto, assim como em muitas igrejas

12 Ibidem 
António da Silva Leite e a música para voz e três órgãos do Convento de Santa Clara... Rosana Marreco Brescia

conventuais ou paroquiais do país, uma das caixas - no caso de Santa Clara, a da Epístola - sempre esteve vazia e nunca conteve um instrumento dentro, servindo apenas para atender à simetria visual do templo (BRESCIA, 2017, p. 43-52).

Figura 2 - Interior da Igreja do antigo Convento de Santa Clara do Porto

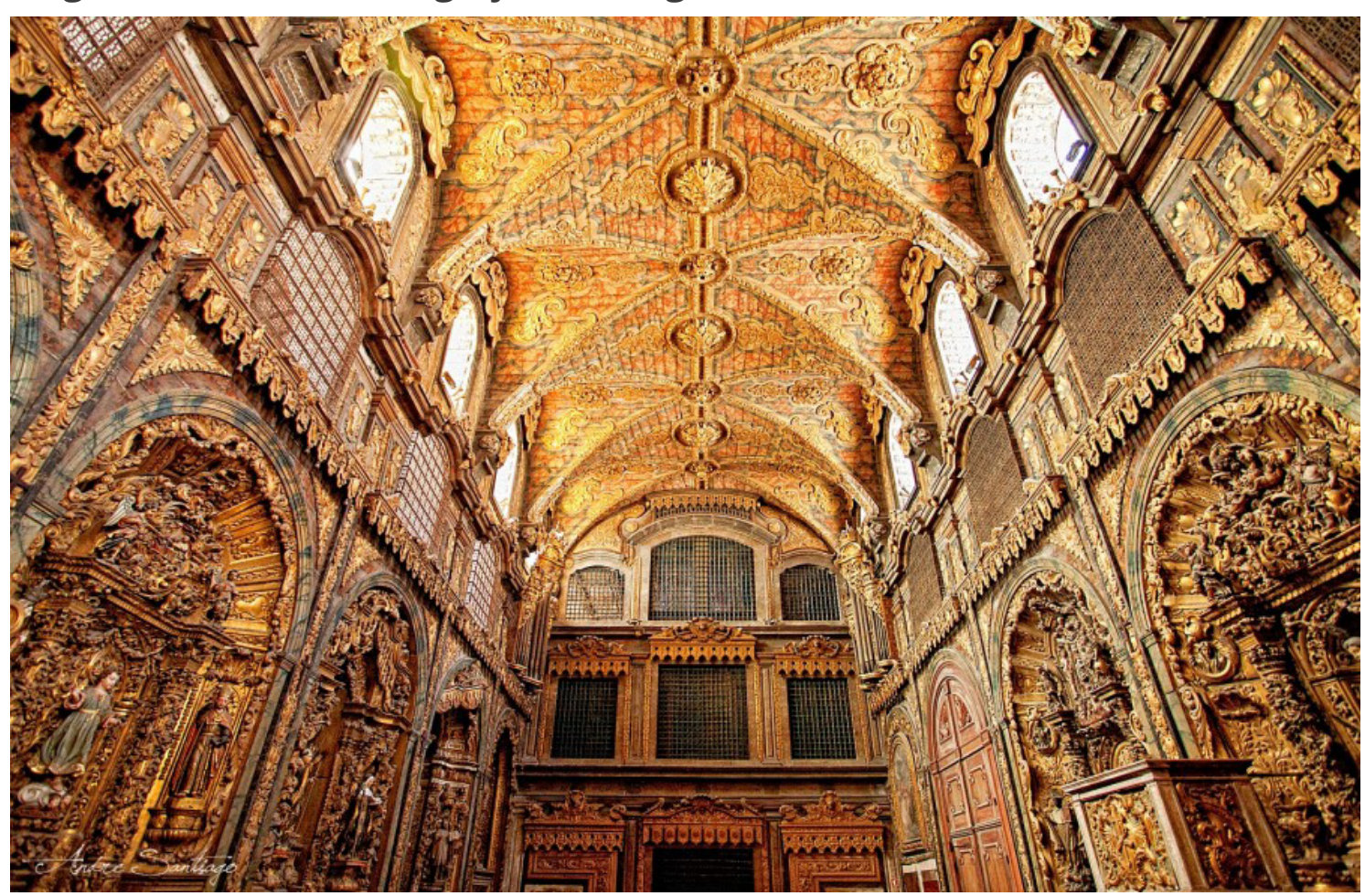

Fonte: fotografia da autora

Já o órgão do Evangelho foi provavelmente construído pelo organeiro Manuel Lourenço da Conceição, organeiro responsável pelos dois órgãos simétricos da Sé Catedral do Porto, construídos entre os anos de 1727 e 1733 (BRESCIA, 2017, p. 53-67). Como é natural no caso de instrumentos tão complexos e com grande uso, o órgão grande de Santa Clara passou por algumas intervenções ao longo dos anos, tendo sido possivelmente intervencionado pelo organeiro galego ativo em Portugal Francisco António de Solha, ou por um de seus discípulos, entre as décadas de 1770 e 1780. Tal atribuição se deve ao fato de que a composição dos registos que 
António da Silva Leite e a música para voz e três órgãos do Convento de Santa Clara... Rosana Marreco Brescia

se lê na consola ser muito similar a dos órgãos de autoria de Solha e da sua escola (BRESCIA, 2013).

O menor e mais antigo órgão de Santa Clara é um realejo provavelmente datado do período joanino, segundo corroboram a extensão do teclado manual - 45 teclas (C-D-E-F-G-A-B-H - c'/c's $\left.C^{\prime \prime \prime}\right)$, com oitava curta e a decoração da respetiva caixa.

\section{Figura 3 - Órgão positivo pertencente ao antigo Convento de Santa Clara da cidade do Porto}

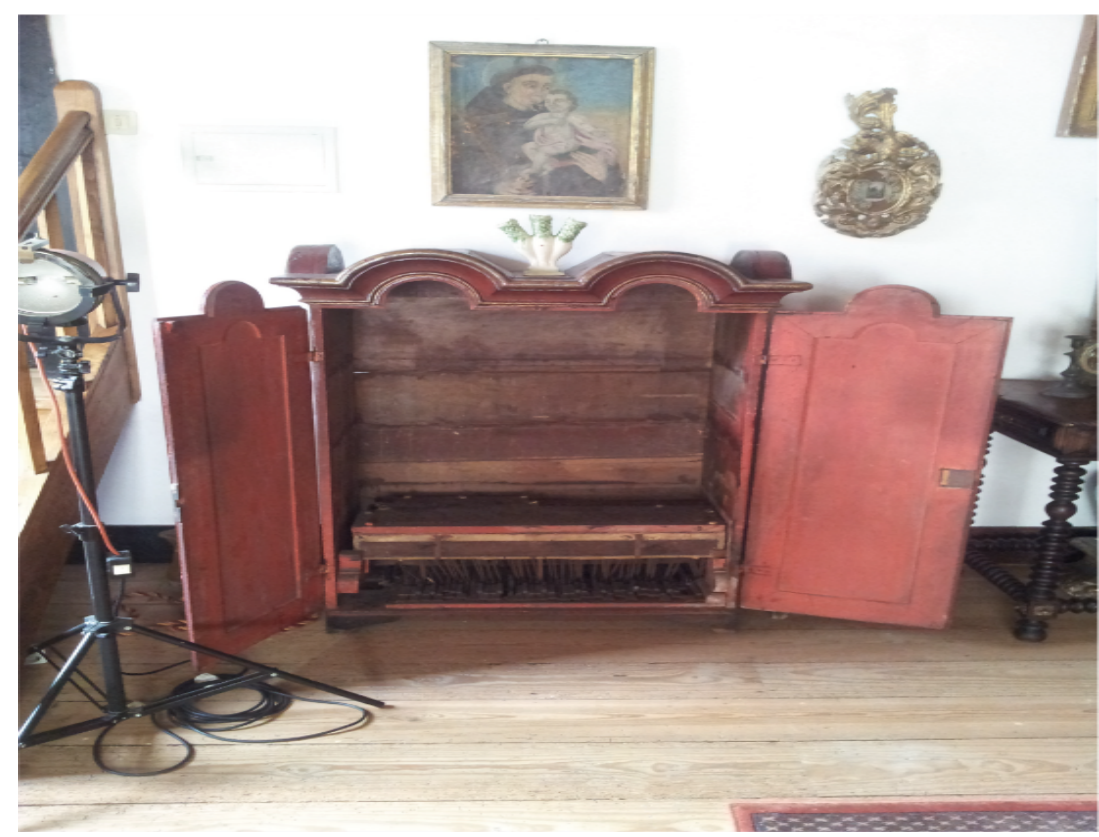

Fonte: fotografia da autora.

O terceiro e mais recente instrumento é um realejo de maiores proporções, com teclado manual de 54 teclas ( $C$ - c'/c's - $\left.f^{\prime \prime \prime}\right)$ e seis meios registos, dotado de pisantes anuladores de cheios. Tratase de um órgão histórico de tipo português (VAZ, 2011, p. 8) ${ }^{13}$, certamente de autoria do organeiro Manuel de Sá Couto, o mais

\footnotetext{
130 repertório organístico português da virada dos séculos XVIII para o XIX revela uma completa adaptação aos instrumentos portugueses da época, dotados de pisantes anuladores de Cheios, que permitem a realização de alternâncias imediatas entre os Fundos e os Cheios realizadas sempre num mesmo teclado manual. Segundo João Vaz: "é lícito, pois, afirmar que Portugal assiste nos finais do século XVIII, através da ação de organistas como Fr. José Marques e Silva e de organeiros como António Xavier Machado e Cerveira ou Joaquim António Peres Fontanes, ao desenvolver de uma forma diferente de conceber a música para órgão que, sem quebrar uma continuidade de séculos, se afastou dos modelos espanhóis ao absorver gradualmente influências italianas (tanto no plano musical como organológico) e que veio a sucumbir às convulsões políticas e sociais provocadas pela implantação definitiva do Liberalismo, à eliminação das entidades promotoras da música sacra no Antigo Regime e às consequentes mudanças operadas no gosto musical português".
} 
António da Silva Leite e a música para voz e três órgãos do Convento de Santa Clara... Rosana Marreco Brescia

importante organeiro do norte de Portugal no primeiro terço do século XIX (BRESCIA, 2020, p. 88).

Figura 4 - Órgão positivo do antigo Convento de Santa Clara do Porto

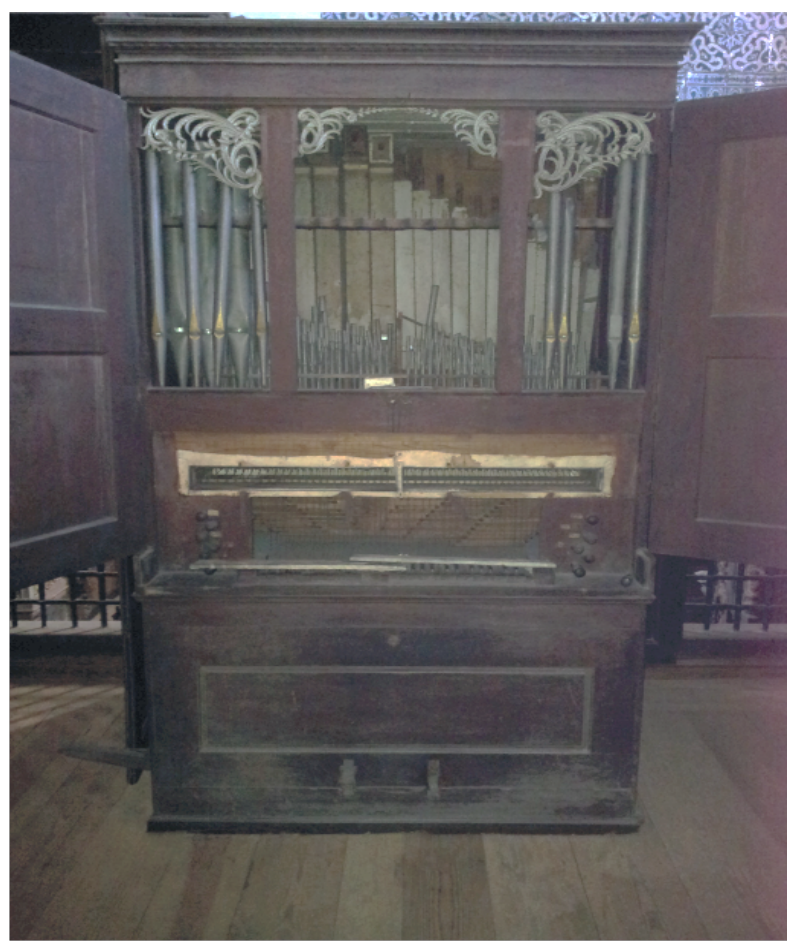

Fig. 4 - Órgão positivo do antigo Convento de Santa Clara do Porto.

A compra do terceiro instrumento, em 1803, e a consequente adequação dos dois instrumentos mais antigos no que tange ao temperamento e diapasão para que todos os três órgãos fossem utilizados ao mesmo tempo, possibilitou aos compositores que trabalhavam para o convento a produção de um repertório único. Das mais de 50 obras escritas para dois ou três órgãos conservadas na Biblioteca Nacional de Portugal pertencentes aos conventos femininos do Porto, ao menos 21 são para três instrumentos. Trata-se de um fato absolutamente singular no contexto da música portuguesa de finais do Antigo Regime, já que, ao contrário do Convento de Mafra, onde foi sucessivamente erigido um conjunto monumental de seis instrumentos de entonação de 24 palmos (c. 1740/ c. 170 / 1792-1807), o Convento de Santa Clara contava com três instrumentos de características organológicas completamente 
António da Silva Leite e a música para voz e três órgãos do Convento de Santa Clara... Rosana Marreco Brescia

diferentes, adaptados por vontade das religiosas musicistas de princípios do século XIX para que soassem como um conjunto orgânico homogéneo.

Segue uma lista preliminar das obras com acompanhamento de três órgãos preservadas na seção de música da Biblioteca Nacional de Portugal.

\begin{tabular}{|c|c|c|c|c|c|c|}
\hline Nome da obra & Data & Compositor & Instrumentação & Dedicatória & Convento & Quota BNP \\
\hline $\begin{array}{c}\text { Gradual do } \\
\text { SS.mo Natal de } \\
\text { N.S.J.C. }\end{array}$ & 1803 & $\begin{array}{l}\text { António da } \\
\text { Silva Leite }\end{array}$ & $\begin{array}{l}\text { SSS, } 2 \text { violinos } \\
\text { e } 2 \text { órgãos }\end{array}$ & $\begin{array}{l}\text { Para uzo das } \\
\text { Relegiozas } \\
\text { de S.ta Clara } \\
\text { da Cidade do } \\
\text { Porto }\end{array}$ & $\begin{array}{c}\text { Santa Clara } \\
\text { Porto }\end{array}$ & $\begin{array}{l}\text { M.M.1231//1- } \\
10\end{array}$ \\
\hline $\begin{array}{l}\text { Offertorio da } \\
\text { Missa do SS.MO } \\
\text { Natal de N.S.J.C } \\
\text { Laetentur coeli }\end{array}$ & 1803 & $\begin{array}{l}\text { António da } \\
\text { Silva Leite }\end{array}$ & $\begin{array}{l}\text { SSSB e } 3 \text { ór- } \\
\text { gãos }\end{array}$ & & $\begin{array}{c}\text { Santa Clara } \\
\text { Porto }\end{array}$ & M.M. 292//2 \\
\hline Miserere a 6 & 1804 & $\begin{array}{l}\text { António da } \\
\text { Silva Leite }\end{array}$ & $\begin{array}{l}\text { SSSSAB e } 2 \text { ór- } \\
\text { gãos (posterior- } \\
\text { mente adaptada } \\
\text { para } 3 \text { órgãos) }\end{array}$ & & $\begin{array}{c}\text { Convento de } \\
\text { Santa Clara de } \\
\text { Vila do Conde, } \\
\text { posteriormente } \\
\text { adaptado para } \\
\text { ser executado } \\
\text { no Convento de } \\
\text { Santa Clara do } \\
\text { Porto }\end{array}$ & $\begin{array}{c}\text { M.M. 740//1- } \\
18\end{array}$ \\
\hline $\begin{array}{c}\text { Responsórios } \\
\text { das Matinas do } \\
\text { Natal }\end{array}$ & 1803 & $\begin{array}{l}\text { António da } \\
\text { Silva Leite }\end{array}$ & $\begin{array}{l}\text { SSSB e } 3 \text { ór- } \\
\text { gãos }\end{array}$ & & $\begin{array}{c}\text { Santa Clara } \\
\text { Porto }\end{array}$ & M.M. 292//4 \\
\hline $\begin{array}{l}\text { Verso Ecce enim/ } \\
\text { Averte faciem }\end{array}$ & 1805 & $\begin{array}{l}\text { António da } \\
\text { Silva Leite }\end{array}$ & $\begin{array}{l}\text { SSSB e } 3 \text { ór- } \\
\text { gãos }\end{array}$ & $\begin{array}{c}\text { Para uso da } \\
\text { Ex.ma S.ra D. } \\
\text { Maria Peregri- } \\
\text { na Religioza } \\
\text { em S.ta Clara } \\
\text { do Porto }\end{array}$ & $\begin{array}{c}\text { Santa Clara } \\
\text { Porto }\end{array}$ & $\begin{array}{c}\text { M.M. } 609 / / 1- \\
3\end{array}$ \\
\hline $\begin{array}{l}\text { Verso Stabat } \\
\text { Mater } \\
\text { Partitura de José } \\
\text { Joaquim dos } \\
\text { Santos adaptada } \\
\text { para } 3 \text { órgãos } \\
\text { por António da } \\
\text { Silva Leite (par- } \\
\text { tes dos órgãos } \\
\text { de Silva Leite) }\end{array}$ & 1805 & $\begin{array}{l}\text { António da } \\
\text { Silva Leite }\end{array}$ & SSB e 3 órgãos & & $\begin{array}{c}\text { Santa Clara } \\
\text { Porto }\end{array}$ & $\begin{array}{c}\text { M.M. } \\
\text { 1736//1-16 }\end{array}$ \\
\hline
\end{tabular}


António da Silva Leite e a música para voz e três órgãos do Convento de Santa Clara... Rosana Marreco Brescia

\begin{tabular}{|c|c|c|c|c|c|c|}
\hline $\begin{array}{c}\text { Dueto de Sopra- } \\
\text { no e Alto } \\
\text { Date Domino } \\
\text { Gloriam nomine } \\
\text { ejus }\end{array}$ & 1805 & $\begin{array}{l}\text { António da } \\
\text { Silva Leite }\end{array}$ & $\begin{array}{l}\text { Dueto SA (ou } \\
\text { SS), } 3 \text { órgãos } \\
\text { (órgão pequeno, } \\
\text { grande e cifrado) }\end{array}$ & $\begin{array}{c}\text { Para uso } \\
\text { das Ex.mas } \\
\text { S.ra D. Ma. } \\
\text { Roberta e D. } \\
\text { Maria Peregri- } \\
\text { na, Religiozas } \\
\text { em S.ta Clara } \\
\text { da Cid.e do } \\
\text { Porto }\end{array}$ & $\begin{array}{c}\text { Santa Clara } \\
\text { Porto }\end{array}$ & M.M. 312//5 \\
\hline $\begin{array}{c}\text { Verso } \\
\text { Hodie illuxit } \\
\text { nobis dies }\end{array}$ & 1808 & $\begin{array}{l}\text { António da } \\
\text { Silva Leite }\end{array}$ & $\begin{array}{l}\text { Soprano e } 3 \\
\text { órgãos }\end{array}$ & $\begin{array}{l}\text { Para uso } \\
\text { das Ex.mas } \\
\text { S.ra D. Ma. } \\
\text { Roberta e D. } \\
\text { Maria Peregri- } \\
\text { na, Religiozas } \\
\text { em S.ta Clara } \\
\text { da Cid.e do } \\
\text { Porto }\end{array}$ & $\begin{array}{c}\text { Santa Clara } \\
\text { Porto }\end{array}$ & $\begin{array}{c}\text { M.M. } \\
1547 / / 1-5\end{array}$ \\
\hline $\begin{array}{c}\text { Psalmo } 129 \\
\text { De Profundis } \\
\text { clamavit ad te }\end{array}$ & 1811 & $\begin{array}{l}\text { António da } \\
\text { Silva Leite }\end{array}$ & $\begin{array}{l}\text { SSSB e } 2 \text { ór- } \\
\text { gãos }\end{array}$ & & $? ? ?$ & $\begin{array}{c}\text { M.M. 943//1- } \\
8\end{array}$ \\
\hline $\begin{array}{l}\text { Responsório } 6^{\circ} \\
\text { Sancta et Imma- } \\
\text { culata Virginitas }\end{array}$ & s.d & $\begin{array}{l}\text { António da } \\
\text { Silva Leite }\end{array}$ & SSB e 3 órgãos. & & $\begin{array}{c}\text { Santa Clara } \\
\text { Porto }\end{array}$ & M.M. 2987 \\
\hline $\begin{array}{l}\text { In } 3^{\circ} \text { Nocturno - } \\
\text { Responsório } 7^{\circ}\end{array}$ & s.d & $\begin{array}{l}\text { António da } \\
\text { Silva Leite }\end{array}$ & $\begin{array}{l}\text { SSSB e } 3 \text { ór- } \\
\text { gãos }\end{array}$ & & $\begin{array}{c}\text { Santa Clara } \\
\text { Porto }\end{array}$ & $\begin{array}{c}\text { M.M. } \\
\text { 1544//1-10 }\end{array}$ \\
\hline Responsório $1^{\circ}$ & s.d & $\begin{array}{l}\text { António da } \\
\text { Silva Leite }\end{array}$ & $\begin{array}{c}\text { [faltam as } \\
\text { partes do canto] } \\
3 \text { órgãos }\end{array}$ & & $\begin{array}{c}\text { Santa Clara } \\
\text { Porto }\end{array}$ & $\begin{array}{c}\text { M.M. } \\
1548 / / 1-3\end{array}$ \\
\hline $\begin{array}{c}\text { Responsório } 2^{\circ} \\
\text { Hodie nobis de } \\
\text { coelo }\end{array}$ & s.d & $\begin{array}{l}\text { António da } \\
\text { Silva Leite }\end{array}$ & $\begin{array}{l}\text { SSSB e } 3 \text { ór- } \\
\text { gãos }\end{array}$ & & $\begin{array}{c}\text { Santa Clara } \\
\text { Porto }\end{array}$ & $\begin{array}{c}\text { M.M. } \\
1549 / / 1-4\end{array}$ \\
\hline $\begin{array}{c}\text { Responsório } 3^{\circ} \\
\text { Quem vidistis } \\
\text { pastores }\end{array}$ & s.d & $\begin{array}{l}\text { António da } \\
\text { Silva Leite }\end{array}$ & $\begin{array}{l}\text { SSSB e } 3 \text { ór- } \\
\text { gãos }\end{array}$ & & $\begin{array}{c}\text { Santa Clara } \\
\text { Porto }\end{array}$ & $\begin{array}{c}\text { M.M. } \\
1550 / / 1-4\end{array}$ \\
\hline $\begin{array}{c}\text { Hymno do Natal: } \\
\text { Hymno das Vers- } \\
\text { peras } \\
\text { Tu lume net } \\
\text { splendor Patris } \\
\text { Jesu Redemptor } \\
\text { omnium } \\
\end{array}$ & s.d & $\begin{array}{l}\text { António da } \\
\text { Silva Leite }\end{array}$ & $\begin{array}{l}\text { SSSB e } 3 \text { or- } \\
\text { gãos }\end{array}$ & & $\begin{array}{c}\text { Santa Clara } \\
\text { Porto }\end{array}$ & $\begin{array}{c}\text { M.M. } \\
\text { 1068//1-16 }\end{array}$ \\
\hline $8^{\circ}$ Responsório & s.d & $\begin{array}{l}\text { António da } \\
\text { Silva Leite }\end{array}$ & $\begin{array}{l}\text { SSSB e } 3 \text { or- } \\
\text { gãos }\end{array}$ & & $\begin{array}{c}\text { Santa Clara } \\
\text { Porto }\end{array}$ & $\begin{array}{c}\text { M.M.1545//1 } \\
4\end{array}$ \\
\hline $\begin{array}{c}\text { Dueto de Sopra- } \\
\text { no e Alto } \\
\text { Date Domino } \\
\text { Gloriam nomine } \\
\text { ejus }\end{array}$ & 1805 & $\begin{array}{l}\text { António } \\
\text { da Silva } \\
\text { Leite }\end{array}$ & SA, 3 órgãos & $\begin{array}{l}\text { Para uso } \\
\text { das Exmas. } \\
\text { Sras. D. Maria } \\
\text { Roberta e Ma- } \\
\text { ria Peregrina }\end{array}$ & $\begin{array}{c}\text { Convento de } \\
\text { Santa Clara do } \\
\text { Porto }\end{array}$ & M.M. 312//5 \\
\hline
\end{tabular}


António da Silva Leite e a música para voz e três órgãos do Convento de Santa Clara... Rosana Marreco Brescia

\begin{tabular}{|c|c|c|c|c|c|}
\hline $\begin{array}{l}\text { Optimam par- } \\
\text { tem com outra } \\
\text { letra Ó Santíssi- } \\
\text { mo Coração de } \\
\text { Jesus }\end{array}$ & & $\begin{array}{l}\text { Francisco } \\
\text { de São Boa- } \\
\text { ventura }\end{array}$ & $\begin{array}{c}3 \text { coros } \\
\text { (grande do maio, } \\
\text { grade do órgão } \\
\text { pequeno, grade } \\
\text { do órgão gran- } \\
\text { de), } 3 \text { órgãos, } 2 \\
\text { violinos, baixo } \\
\text { (figurado) }\end{array}$ & $\begin{array}{l}\text { Convento de } \\
\text { Santa Clara do } \\
\text { Porto ??? }\end{array}$ & $\begin{array}{c}\text { M.M. } \\
\text { 1796//1-26 }\end{array}$ \\
\hline Hymno do Natal & s.d & $\begin{array}{l}\text { António da } \\
\text { Silva Leite }\end{array}$ & SSSB, 3 órgãos & & $\begin{array}{c}\text { M.M. } \\
\text { 1068//1-16 }\end{array}$ \\
\hline $8^{\circ}$ Responsorio & s.d & $\begin{array}{l}\text { António da } \\
\text { Silva Leite }\end{array}$ & SSSB, 3 órgãos & & $\begin{array}{c}\text { M.M. } \\
\text { 1545//1-4 }\end{array}$ \\
\hline $\begin{array}{c}\text { 5 Responsório } \\
\text { "Beata Dei Geni- } \\
\text { trix" }\end{array}$ & s.d & $\begin{array}{l}\text { António da } \\
\text { Silva Leite }\end{array}$ & SSSB, 3 órgãos & & $\begin{array}{c}\text { M.M. } \\
\text { 1564//1-7 }\end{array}$ \\
\hline
\end{tabular}

Fonte: a autora.

O singular repertório para três órgãos composto a partir de 1803 é geralmente escrito para vozes e órgãos. Algumas obras trazem o nome da religiosa responsável pela comissão, como as conhecidas cantoras Maria Peregrina, Maria Roberta, Quitéria Emília e Rita Roberta. O particular uso dos instrumentos também é digno de menção. Em quase todos os manuscritos, os compositores descrevem os instrumentos como "órgão cifrado" - pequeno e mais antigo realejo, geralmente utilizado como baixo contínuo, dando apoio extra às freiras que cantavam no coro alto -, "órgão grande" e "órgão novo" ou "órgão pequeno", que dialogavam com mais frequência, sendo o grande utilizado quase sempre como tutti, enquanto o novo era o real acompanhamento das vozes solistas ou coristas, em organo obbligato.

Tal uso é completamente justificável, já que o órgão grande tem uma colocação bastante peculiar dentro do templo. Com o intuito de que a freira organista ficasse completamente oculta aos olhos mundanos, a consola do instrumento foi colocada em um estreito corredor, o que praticamente impede não só a visão do altar-mor como também reduz significativamente a visão que a organista poderia ter das solistas ou coristas posicionadas no coro alto. Ainda assim, a implantação do grande instrumento do Convento de Santa Clara não inviabilizou a prática de música em conjunto, como comprovam os manuscritos preservados. 
António da Silva Leite e a música para voz e três órgãos do Convento de Santa Clara... Rosana Marreco Brescia

Com a extinção das ordens religiosas em 1834 e a consequente secularização dos bens da igreja, os conventos femininos foram duramente atingidos. Apesar de as freiras não terem sido expulsas do país, como foi o caso dos monges, os conventos foram impedidos de aceitar novas noviças, o que afetou inexoravelmente as receitas dessas instituições. Com menos receitas, é natural que o número de composições escritas para ocasiões especiais diminuísse drasticamente, e que os dias de glória no que tange à música conventual portuguesa ficassem para trás.

O convento de Santa Clara foi extinto definitivamente em 1900, com a morte da última freira, contudo, ao contrário do que aconteceu em diversos conventos femininos em Portugal, a Igreja, os três órgãos e um grande número de partituras manuscritas um valiosíssimo património imaterial da cidade do Porto e mesmo de Portugal - foram preservados, embora em distintos estados de conservação. Essa manutenção permite perceber e admirar a gloriosa atividade musical desenvolvida no convento das clarissas portuenses em finais do século XVIII e princípios do século XIX, quando as suas freiras musicistas - grandes mecenas das artes - comissionaram e interpretaram algumas das mais criativas e vibrantes páginas da música portuguesa de finais do Antigo Regime.

\title{
Referências
}

\author{
AZEVEDO, Carlos de. A cidade do Porto nos relatórios das visitas «ad \\ limina» do arquivo do Vaticano. Revista de História - O Porto na \\ Época Moderna, Porto, v.l, 175-204, 1979.
}

BECKFORD, William. A Corte da Rainha D. Maria I: Correspondência de William Beckford 1787. Lisboa: Livraria Editora Tavares Cardoso \& Irmão, 1901. 191p.

BESSA, Rui Manuel. António da Silva Leite: criatividade e "moda" na música romântica portuense. Tese de doutoramento. Faculdade de Letras da Universidade de Coimbra, 2008. Coimbra: Universidade de Coimbra, 2008. 436p. 
António da Silva Leite e a música para voz e três órgãos do Convento de Santa Clara... Rosana Marreco Brescia

BRESCIA, Marco. Órgão José Joaquim da Fonseca (c. 1863) e a Organaria Histórica Portuguesa. Lisboa: Castelpor, 2020.135p.

BRESCIA, Marco. Simetria visual e sonora do órgão ibérico em Portugal: o pioneirismo da Sé do Porto. In: Restauro dos Órgãos da Epístola e do Evangelho da Sé Catedral do Porto. Porto: Cabido Portucalense; Lavra: Letras e Coisas, 2017. p. 43-52.

BRESCIA, Marco. Manoel Lourenço da Conceição e os órgãos da Sé do Porto: rumo à plena afirmação do órgão ibérico em Portugal. In: Restauro dos Órgãos da Epístola e do Evangelho da Sé Catedral do Porto. Porto: Cabido Portucalense; Lavra: Letras e Coisas, 2017. p. 53-67. BRESCIA, Marco. L'école Echevarría en Galice et son rayonnement au Portugal. Tese de Doutorado. École Doctorale V, Concepts et Langages da Université Paris IV - Sorbonne, 2013. Paris: Université Paris IV Sorbonne, 2013. 555p.

CORREIO DO PORTO, Porto: 5 de fevereiro de 1830.

COSTA, Padre António Carvalho. Corografia Portugueza. Lisboa: Officina de Valentim da Costa Deslandes, 1706-1712. $1^{\circ}$ volume, 552p. CRANMER, David. Da inauguração aos alvores do Miguelismo: actividades teatrais e repertórios do Teatro de S. João (1798-1827). In: CYMBRON, Luisa; VASCONCELOS, Ana Isabel (org.). O Velho Teatro de S. João (1798-1908): teatro e música no Porto do longo século XIX. Porto: Edições Afastamentos, 2020. p.147-175.

DIVERTIMENTO PARA ÓRGÃo dedicado a Ex.ma Snr.a D. a Camila Henriqueta de Saldanha. BNP, m.m. 4514.

FERNANDES, Cristina. A Música no contexto da cerimónia da Profissão nos mosteiros femininos portugueses (1789-1828). Revista Portuguesa de Musicologia, Lisboa, 7-8, p.59-94, 1997/1998.

FERNANDES, Maria Eugênia Matos. O Mosteiro de Santa Clara do Porto em meados do séc. XVIII (1730-1780). Porto: Arquivo Histórico \& Câmara Municipal do Porto, 1992. 292p.

GAITA DESCANÇADA / DISCURSO PARA ÓRGÃO dedicada a III.a Soror Catharina Candida. BNP, m.m. 1227. 
António da Silva Leite e a música para voz e três órgãos do Convento de Santa Clara... Rosana Marreco Brescia

JORNAL DE MODINHAS com acompanhamento de Cravo pelos melhores autores. Lisboa: Francisco Domingos Milcent, 1795. Ano 3, n¹2. BNP, M.P.P. 46//60 A.

LA GRISELDA, drama eroicomico per musica da rappresentarsi nel Regio Teatro di S. Giovanni in ossequio del felicissimo giorno natalizio del Serenissimo Principe del Brazile D. João nel di 13 Maggio 1806. Porto: Stamperia di Antonio Alvarez Ribeiro, 1806. 123p. FLUC, Colecção Jorge de Faria [26-1-6; 26-1-46]

LA MORTE DI CLEOPATRA, tragedia para música offerecida à IIIma , e Exma, Senhora D. Thomasia Francisca de Mello Breyner, por Marianna Scaramelli... do Real Theatro de S. João, para nelle se representar no dia do seu benefício 8 de novembro de 1807. Porto: Typographia de Antonio Alvarez Ribeiro, 1807. 48p. Música de Sebastiano Nasolini. FLUC, Colecção Jorge de Faria [25-1-107; 33-5-39]

LOPES, Maria Antónia. Mulheres, espaço e sociabilidade ( $2^{a}$ metade do século XVIII). Lisboa: Livros Horizonte, 1989. 232p.

MONSON, Craig A. Divas in the Convent: nuns, music \& defiance in 17th century Italy. Chicago \& London: Chicago University Press, 2012. $272 p$.

MORUJÃO, Isabel. Entre a voz e o silêncio: literatura e espiritualidade nos mosteiros femininos. Revista Rever, São Paulo: Pontifícia Universidade Católica de São Paulo, Ano 11, n 01, p. 35-54, Jan/Jun 2011.

O LEAL PORTUGUÊS, Porto, 5 de outubro de 1808, Suplemento n 14.

O TRIPEIRO, Porto, Junho de 1909, Ano I, nº 34.

O TRIPEIRO, Porto, Outubro de 1931, IVª série, $n^{\circ} 12$.

SILVA, Francisco Inocêncio da. Diccionario Bibliographico Portuguez: estudos de Innocencio Francisco da Silva aplicáveis a Portugal e ao Brasil. Tomo Oitavo. Lisboa: Imprensa Nacional, 1867. 428p.

SILVA LEITE António da. Estudo de Guitarra em que se expõem o meio mais fácil para aprender a tocar este instrumento. Porto: $\mathrm{Na}$ oficina Typografica de Antonio Alvarez Ribeiro, 1796. 64p. 
António da Silva Leite e a música para voz e três órgãos do Convento de Santa Clara... Rosana Marreco Brescia

SILVA LEITE António da. Em Applauso da Exc.ma Snr.a D. Anna Candida no dia dos seus anos, e no qual fez a sua solemne profissão no Real Convento das Religiosas de Santa Clara da Cidade do Porto...: Soneto. Porto: Imprensa do Gandra, 1826. BNP, L.598//10 A. SILVA LEITE António da. LECTIO VII a órgão solo. BNP, m.m. 1227. SILVA LEITE António da. LECTIO $6^{\mathrm{a}}$ in Coena Domini. BNP, m.m. 2149. SILVA LEITE António da. Soneto em Applauso da III.ma e ex.ma Sr. D. Maria Barbara Bellon, sendo Reeleita Abbadessa do R. Convento da Madre de Deos de Monchique e Juntamente de sua nova Vigaria a Ex.ma Sr. D. Anna Candida. Porto: Typ. Yiuva Alvarez Riberio \& Filhos, 1829.

SMITH, Robert. A Talha em Portugal. Lisboa: Livros Horizonte, 1963. 198p. STEVENSON, Robert. Leite, António (Joaquim) da Silva. In: SADIE, Stanley. The New Grove Dictionary of Music and Musicians. $2^{a}$ Edição. Londres: Macmillan, 2001. Disponível em https://doi. org/10.1093/gmo/9781561592630.article.16358

VAZ, João. José Marques e Silva Obras completas para órgão. Porto: Universidade Católica Portuguesa, Centro de Investigação em Ciência e Tecnologia das Artes, 2011. 55p.

VIEIRA, Ernesto. Dicionario Biographico de Musicos Portuguezes. $2^{\circ}$ Volume. Lisboa: Typographia Mattos Moreira \& Pinheiro, 1900. 550p.

\section{Publisher}

Universidade Federal de Goiás. Escola de Música e Artes Cênicas. Programa de Pós-graduação em Música. Publicação no Portal de Periódicos UFG.

As ideias expressadas neste artigo são de responsabilidade de seus autores, não representando, necessariamente, a opinião dos editores ou da universidade. 